Marcio N. Boia 1

Leonardo P. da Motta 1

Maria do Socorro P. Salazar 1

Martha P. Suarez Mutis 1

Rilza B. A. Coutinho 1

J. Rodrigues Coura 1

\section{Estudo das parasitoses intestinais e da infecção chagásica no Município de Novo Airão, Estado do Amazonas, Brasil}

\author{
Cross-sectional study of intestinal parasites and \\ Chagas' disease in the Municipality of Novo Airão, \\ State of Amazonas, Brazil
}

1 Departamento de Medicina Tropical, Instituto Oswaldo Cruz, Fundação Oswaldo Cruz. Av. Brasil 4365, C. P. 926, Rio de Janeiro, RJ 21045-900, Brasil.
A bstract A cross-sectional study was performed on the residents of one in every ten households in the town of Novo Airão, in the northern meso-region of the State of Amazonas, 250 kilometers from Manaus by riverboat. A family cluster sample of $89 \mathrm{dwellings} \mathrm{was} \mathrm{studied.} \mathrm{A} \mathrm{stool} \mathrm{sample}$ was requested from each of the inhabitants for examination using the Lutz sedimentation and Baermann-Moraes-Coutinho techniques, and blood was taken by venous puncture for Trypanosoma cruzi ELISA antibody testing and immunofluorescence. From a total of 316 stool samples, 87.6\% had one or more parasites: Ascaris lumbricoides (35.1\%), Entamoeba histolytica (29.1\%), Giardia lamblia (17.4\%), and other parasites with lower prevalence rates. These results were directly correl ated with lack of sanitation and clean water supply. Of the 346 sera examined, 16 (4.6\%) were reactive to T. cruzi antibodies, but only three showed a correl ation between this result and human contact with wild triatomines, known locally as "piassava lice".

Key words Chagas' Disease; Trypanosoma cruzi; Parasites; Basic Sanitation

Resumo Foi realizado um estudo seccional descritivo em uma amostra sistemática por conglomerado de uma em cada dez famílias resi dentes na sede do Muni cípio de Novo Airão, na mesoregi ão norte do Estado do Amazonas, a 250 quilômetros de Manaus por via fluvial. De cada um dos resi dentes nos 89 domi cíli os da amostra foram soli citadas fezes para exame pel os métodos de sedimentação de Lutz e pel o Baermann-Moraes-Coutinho e colhido sangue por punção venosa para testes de ELISA e imunofluorescência para pesquisa de anticorpos anti-Trypanosoma cruzi. O exame de 316 amostras de fezes mostrou $87,6 \%$ com um ou mais parasi tos: $35,1 \%$ com Ascaris lumbricoides, 29,1\% com Entamoeba histolytica, 17,4\% com Giardia lamblia e outros parasitos com menor prevalência. Estes resultados foram correlaci onados com a falta de saneamento e de suprimento deágua tratada. De 346 soros examinados 16 (4,6\%) foram reati vos para anti corpos anti-Trypanosoma cruzi, mas somente em três del es houve correl ação entre este resultado e o contacto das pessoas com triatomíneos si l vestres, conheci dos local mente como "piol ho da piaçava".

Palavras-chave Doença de Chagas; Trypanosoma cruzi; Parasi tos; Saneamento Bási co 


\section{Introdução}

Em trabalhos anteriores, Coura et al. (1993a, 1993b, 1994c) estudaram aspectos epidemiológicos, sociais e sanitários de sete localidades rurais do Município de Coarí, no Médio Solimões e de dois bairros periféricos da sede daquele município, comparando-os entre si, e, posteriormente, com um estudo semel hante realizado na sede do Município de Barcelos, no M édio Rio Negro, enfatizando neste último estudo aspectos relacionados às parasitoses intestinais e à infecção chagásica.

As parasitoses intestinais são universalmente distribuídas na Amazônia brasileira, como no país como um todo. Entretanto, apresentam variações inter e intra-regionais, dependendo dos seguintes fatores: constituição do solo; índice de aglomeração da população e de suas condições econômicas, sociais, sanitárias e educacionais; presença de animais no peridomicílio; condições de uso e contaminação do solo, da água e dos alimentos; e da capacidade de evolução das larvas e ovos dos helmintos e de cistos de protozoários em cada um desses ambientes.

São poucos os trabalhos sobre parasitoses intestinais na Amazônia brasileira, particularmente devido à sua grande extensão territorial, baixa densidade demográfica e difícil acesso, destacando-se entre outros os de Costa, 1947; Montenegro, 1947; Moraes, 1959; Oliveira, 1959; Pinheiro et al., 1976; Montoril-Filho et al., 1978; Dias et al., 1991 e mais recentemente os de Coura et al., 1993a, 1993b e 1994c; este último tentando estabelecer comparação entre diferentes localidades dos rios Solimões e Negro.

Até 1969, quando Shaw, Lainson e Frahia descreveram os primeiros casos humanos da doença de Chagas em Belém do Pará, a infecção chagásica era conhecida apenas como uma enzootia silvestre. Desde que Chagas (1924) confirmou como Trypanosoma cruzi tripanossomas isolados por Aben-Athar em macacos da espécie Sai miri sciureus, diversas espécies de animais silvestres, entre marsupiais, quirópteros, roedores, desdentados e primatas, têm sido encontrados como portadoras do T. cruzi na Amazônia brasileira (Deane, 1961, 1964, 1967; Deane \& Damasceno, 1961). Por outro lado, pelo menos 18 espécies de triatomíneos já foram encontrados naquela região, 10 das quais infectadas com T. cruzi ou cruzi like (Almeida, 1971; Almeida \& Machado, 1971; Miles et al., 1981, 1983; Brazil et al., 1985; Barrett \& Guerreiro, 1991; Coura et al., 1994a).

A partir de 1990, tem sido chamada a atenção para os riscos de endemização da doença de Chagas na Amazônia brasileira tanto pelo nosso grupo (Coura, 1990, Coura et al., 1994a, 1994b, 1994c, 1995a, 1995b), quanto pelo grupo do Instituto Evandro Chagas de Belém do Pará (Valente \& Valente, 1993, Valente et al., 1997).

Aqueles riscos estariam ligados à invasão do homem e animais domésticos aos ecótopos silvestres (caçadores e extrativistas, principalmente colhedores de piaçava), à adaptação de triatomíneos e reservatórios silvestres ao domicílio e peridomicílio, particularmente em decorrência dos desmatamentos e colonização desordenados, e à migração de populações humanas portadoras da doença de Chagas de áreas endêmicas para a Amazônia, levando, inclusive, animais e triatomíneos domésticos infectados pelo T. cruzi.

O presente trabalho analisa al guns aspectos epidemiológicos, sociais e sanitários de uma amostra sistemática por conglomerado familiar da população residente na sede do Município de Novo Airão, no Rio Negro, Estado do Amazonas, com especial referência às parasitoses intestinais e à prevalência sorológica da infecção chagásica.

\section{Metodologia}

Localização e características da área

O Município de Novo Airão, com uma área de 38.706 km² localiza-se na mesoregião do norte amazonense e é cortado transversalmente pelo Rio Negro, a $41 \mathrm{~m}$ acima do nível do mar; limita-se com os Municípios de Presidente Figueiredo e Manaus a leste, Iranduba, Manacapuru, Caapi ranga e Codajás ao sul, Barcelos a oeste e com o Estado de Roraima ao norte (Figura 1). A sede do município, onde foi realizado este trabalho, localiza-se na margem direita do Rio $\mathrm{Ne}$ gro, a $250 \mathrm{~km}$ de Manaus por via fluvial.

O relevo do município é composto por uma planura ondulada, cavada por depressões e vales, permeados por numerosos rios e igarapés, pontilhada de lagos e com mais de 400 ilhas dispostas em corrente que formam o arquipélago de Anavil hanas, com 350.000 hectares. $O$ território é composto por densas florestas, com árvores de 40 metros de altura e mais altas, situando-se aí o Parque Nacional de Jaú, com mais de dois milhões de hectares, na bacia do Rio Jaú. O clima é quente e úmido, com altos índices pluviométricos, com temperatura média anual de $26{ }^{\circ} \mathrm{C}$; mínima de $22{ }^{\circ} \mathrm{C}$ e máxima de $30 \circ \mathrm{C}$. O solo é de areia e argila, pouco propício à agricultura de cereais e outras plantações. 


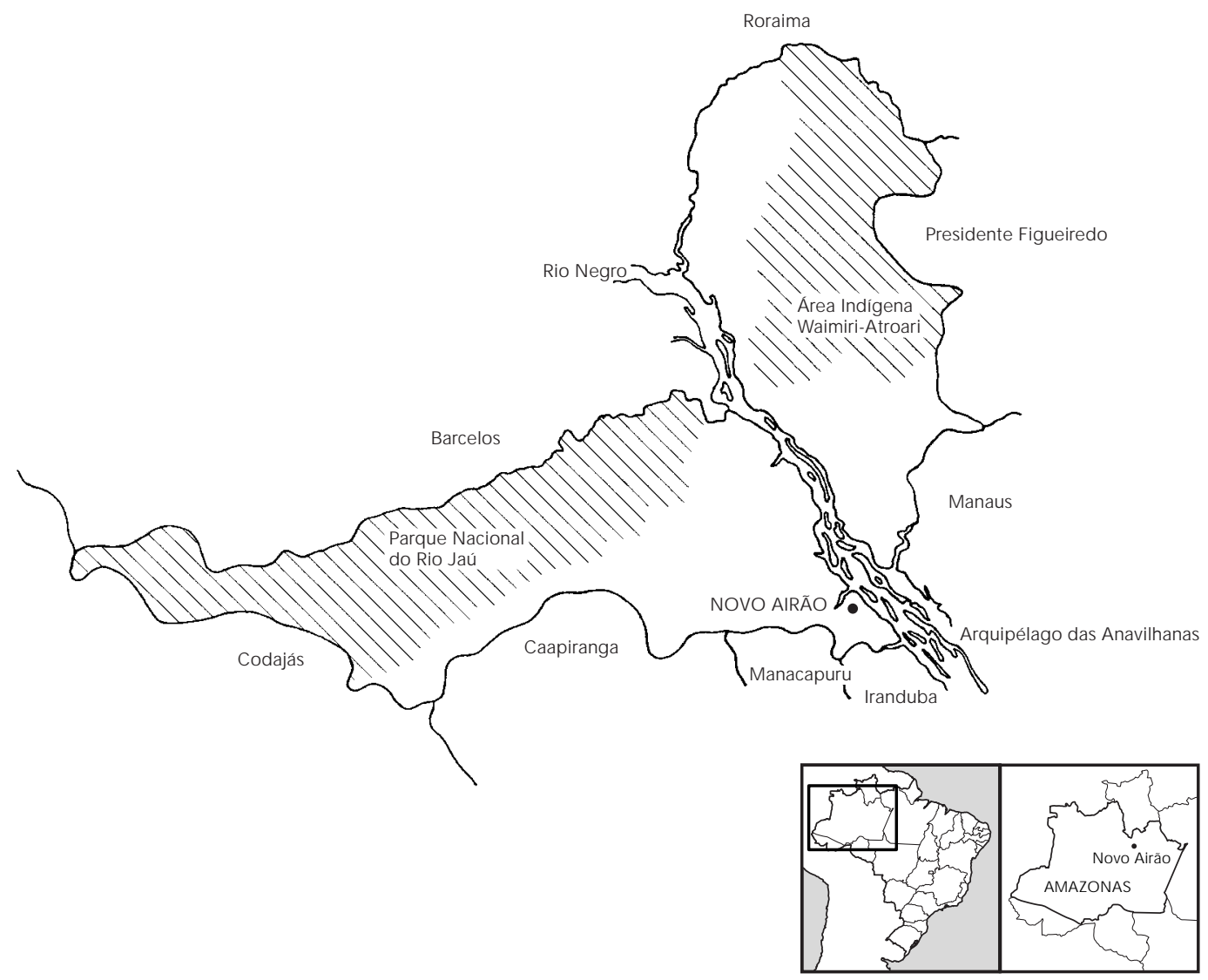

A sede do município possuía, segundo o IBGE (1991), 1072 casas, das quais 944 (88,1\%) habitadas e 128 (11,9\%) desabitadas ou em construção. A maioria das casas era de madeira com cobertura de zinco ou amianto e, em menor proporção, de alvenaria cobertas de amianto. As ruas principais são asfaltadas, com alguns trechos com calçamento do tipo solo-cimento. Os meios de transporte mais comuns são a bicicleta, motocicleta e uns poucos automóveis. O transporte inter-regional é feito predominantemente por via fluvial. Recentemente, introduziu-se uma linha diária de ônibus Manaus-Novo Airão-Manaus.

A sede dispõe de uma agência de correios e de um posto telefônico com sistema DDD; porém, com apenas cinco canais para cerca de 100 telefones na cidade. A energia é termo-elétrica e funciona em média $21 \mathrm{~h} /$ dia. $\mathrm{O}$ abastecimento de água é feito em parte pela Companhia de Saneamento do Amazonas (COSAMA), que cobre aproximadamente $25 \%$ das habitações, predominantemente no Centro e bairro do Remanso. As demais famílias utilizam cinco poços artesiano coletivos, e poucas famílias possuem seus próprios poços.

\section{A mostra e tipo de estudo}

Foi realizado um estudo seccional descritivo, tomando-se uma amostra sistemática por conglomerado familiar de uma em cada 10 casas habitadas, representando aproximadamente $10 \%$ da população residente na sede do Município de Novo Airão. Foram excluídos os estabelecimentos comerciais, escolas, igrejas e prédios públicos.

Inicialmente foi realizado um levantamento do número de casas e habitantes existentes nos seis bairros que compõem a cidade: Centro, Olaria, Murici, Remanso, Anavilhanas e Eduardo Braga. Cada domicílio da amostra (Fi- 
gura 2) foi visitado por uma equipe de dois médicos, alunos do Curso de Mestrado em Medicina Tropical do Instituto Oswaldo Cruz (Fundação Oswaldo (ruz), sob a supervisão de um docente, os quais inicialmente explicavam os objetivos do estudo e obtinham o consentimento da família para realizá-lo.

\section{Instrumentos de Pesquisa}

Foram aplicados dois questionários, um domiciliar, para avaliar as condições físi cas e sanitárias do domicílio, e outro individual, para avaliação das condições clínicas e epidemiológicas da população amostrada.

O primeiro questionário era dirigido ao chefe da família e, na sua ausência, ao cônjuge, ou pessoa mais capacitada a respondê-lo, constando basicamente das condições físicas e sanitárias do domicílio, abastecimento de água e seu tratamento, tratamento do lixo, iluminação do domicílio, fontes de renda familiar, existência de bens duráveis, alimentação familiar, presença ou não de animais domésticos e borrifação do domicílio com inseticidas nos últimos 12 meses.

O segundo questionário (individual) era aplicado a todos os residentes (o das crianças menores, dirigido aos pais) e constava de uma anamnese sobre comportamento individual e antecedentes, hábitos de higiene, envolvimento com o solo, eliminação de vermes, reconhecimento de triatomíneos, manifestações clínicas nos últimos dois meses, atendimento médico e vacinações recebidos. A cada um dos entrevistados foi mostrado uma coleção de triatomíneos, contendo exemplares dos gêneros Rhodnius, Panstrongylus e Triatoma, perguntando-se se os conhecia, se já fora picado, quando e onde. Em seguida, era feito um exa-

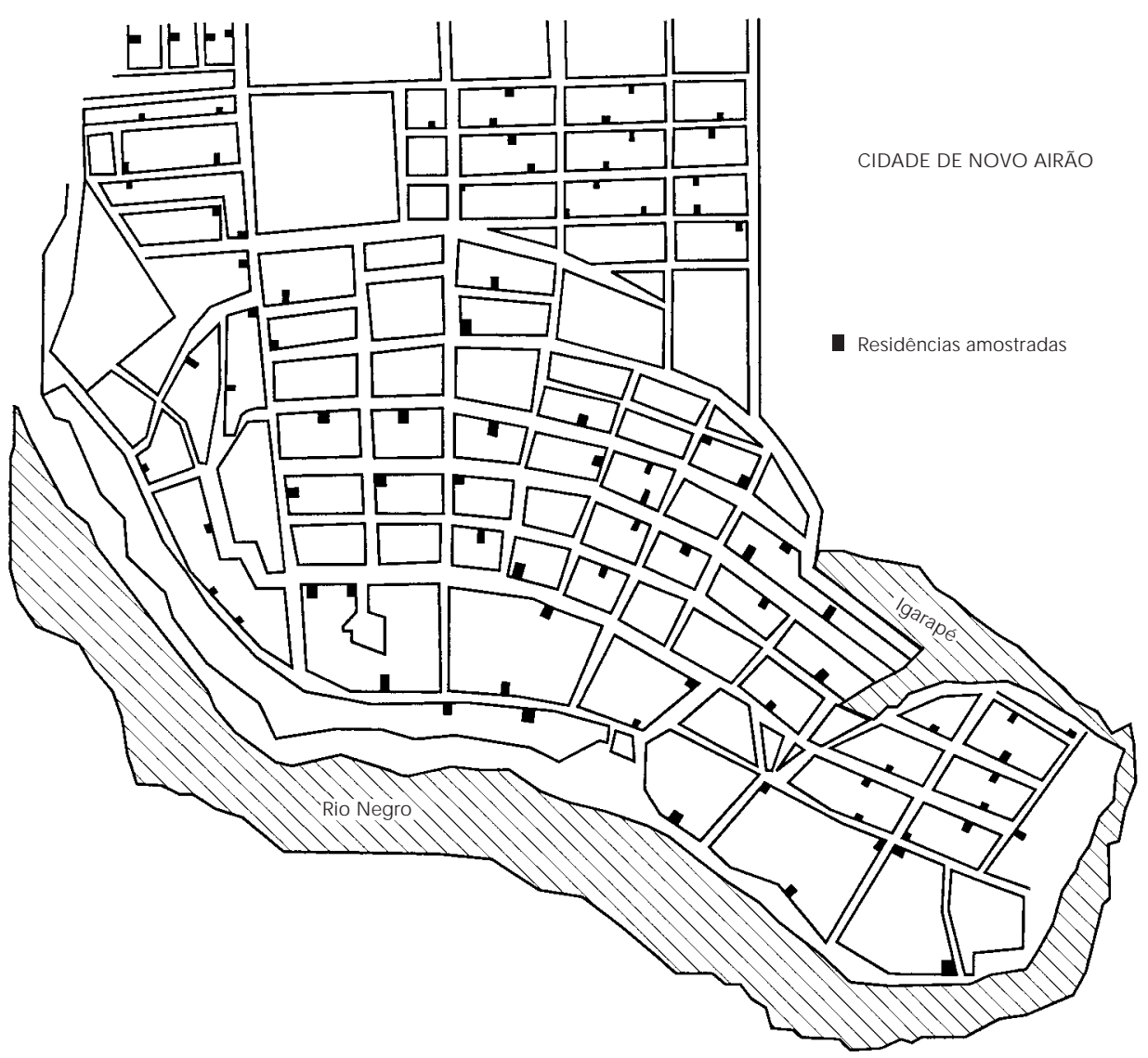


me clínico sumário, verificando-se peso, altura, pressão arterial, espessura da prega cutânea, situação das mucosas visíveis, pele, adenopatia cervical, esplenomegalia, hepatomegalia e ausculta cardíaca e pulmonar. De cada indivíduo com idade superior a dois anos, com ficha individual completa, foi colhido após o seu consentimento, quando adultos, ou de seus pais, no caso de crianças, respectivamente 10 ou 5-6ml de sangue por punção venosa, para exames sorológi cos. Na mesma visita, foram distribuídos recipientes de plásticos devidamente identificados para coleta de fezes para exame parasitológico, os quais eram recolhidos no dia seguinte de manhã pela equipe. $\mathrm{Na}$ ausência de algum dos membros da família, uma nova visita era feita para entrevista e coleta do material.

Dos indivíduos sintomáticos respiratórios (tosse com expectoração por mais de duas semanas) foram colhidas amostras de escarro para baciloscopia. Da mesma forma dos indivíduos febris ou com esplenomegalia foram feitas lâminas com gota espessa e esfregaço de sangue para pesquisa de plasmódio. As pessoas com manifestações de pele sugestiva de hanseníase eram encaminhadas a um dos membros da equipe com experiência no assunto para exame neurodermatológico completo. Os demais pacientes com outras manifestações clínicas importantes eram encaminhados ao hospital local para exames e tratamentos.

Da equipe, além de um técnico com experiência em exame parasitológico de fezes, fez parte também um técnico em entomologia que fez busca ativa de criadores de larvas de anofelinos no perímetro urbano e de flebotomíneos com armadilhas luminosas nas matas próximas.

\section{Procedimentos de laboratório}

As amostras de sangue colhidas por punção venosa eram centrifugadas e separadas alíquotas de soro, as quais eram congeladas para realização de sorologias quando do regresso ao nosso Laboratório no Rio de Janeiro.

A sorologia para infecção chagásica foi realizada pelas técnicas de imunofluorescência indireta e pelo ELISA. No teste de imunofluorescência empregou-se antigamaglobulina IgG (Biolab), utilizando-se como antígeno formas de cultura da cepa Y do T. cruzi formolizadas, com leitura da reação em microscópio de epiiluminação modelo Leitz Dialux, com avaliação qualitativa (positivo ou negativo) em diluição única de l:40. A reação de ELISA foi realizada utilizando-se kit produzido por Biomangui- nhos (Fundação Oswaldo Cruz), com antígenos solúveis purificados de formas de cultura deT. cruzi.

As amostras de fezes foram examinadas pelos métodos de sedimentação de Lutz e pelo Baermann-Morais-Coutinho, por técnico especializado de nossa equipe, em laboratório da própria Unidade Mista de Saúde de Novo Airão.

\section{Resultados}

Nos 89 domicílios componentes da amostra residiam 490 pessoas, correspondendo a uma média de 5,5 pessoas por casa habitada. No entanto, considerando as perdas de $16,4 \%$ de indivíduos que não se encontravam no domicílio durante a visita inicial e em visitas subseqüentes, a nossa amostra foi constituída por um total de 410 pessoas, $47 \%$ do sexo masculino e $53 \%$ do sexo feminino.

\section{Aspectos sanitários}

Apenas $25,8 \%$ das casas da amostra possuem água encanada fornecida pela Companhia da Saneamento do Estado do Amazonas (COSAMA); 53,9\% utilizam-se de cinco poços artesianos distribuídos pela cidade, $19,1 \%$ tem poços individuais; e uma casa utiliza água de cacimba. O armazenamento da água é feito em 42,7\% das casas em vasilhame, 32,6\% em camburão, $18 \%$ em caixas d'água e apenas 6,7\% em cisternas. A utilização da água para beber em 54,5\% das casas é feita sem nenhum tipo de tratamento; em 18,2\%, a água é coada; em $11,4 \%$, é filtrada; em 11,4\%, tratada com hipoclorito; em 4,5\%, fervida; e em uma casa não houve informação.

Das 89 casas da amostra, 51\% possuem apenas uma fossa rudimentar, 32,6\% têm fossa séptica, $14,6 \%$ não têm nenhum tipo de fossa, lançando as fezes a céu aberto, e uma casa lança as fezes no rio.

Em 46,5\% das casas o lixo é cremado, em $37,2 \%$ é recolhido pela Prefeitura Municipal e em $12,8 \%$ é abandonado a céu aberto e o restante é lançado ao rio.

Todas as casas da amostra haviam sido visitadas por agentes da Fundação Nacional de Saúde (FNS) em trabalho de divulgação. No entanto, apenas $25,8 \%$ tinham sido borrifadas com inseticidas, 69,6\% delas nos seis últimos meses e $30,4 \%$ com intervalo maior. 


\section{Parasitoses intestinais}

Dos 410 indivíduos com ficha clínica completa, $287(63,6 \%)$ relatavam passado de eliminação de vermes: 91,1\% pelo ânus; 5,7\% pela boca; e os demais pela boca e ânus, ou pela boca e nariz, 7,3\% dos quais quando do uso de medicação antiparasitária. Foram realizados 316 (77,1\%) exames coproscópicos de pessoas que entregaram amostra de fezes, observando-se uma positividade de parasitos intestinais em $277(87,6 \%)$. A prevalência por faixa etária variou de $73 \%$ a $92,5 \%$, sem diferença com significado estatístico entre elas (Tabela 1).

O Ascaris lumbricoides foi o parasito mais encontrado (35,1\%), e o Enterobius vermicularis, o menos freqüente $(0,1 \%)$ (Tabela 2$)$.

Dos pacientes parasitados, $63,3 \%$ apresentavam apenas um parasito, $17,1 \%$ dois, $5,7 \%$

Tabela 1

Distribuição da prevalência das parasitoses intestinais por faixa etária em 316 pessoas. Novo Airão, Amazonas, 1995.

\begin{tabular}{lccc}
\hline \multirow{2}{*}{ Faixa etária em anos } & \multicolumn{2}{c}{ Positivos } & Total \\
& $n$ & $\%$ & $n$ \\
\hline$<1$ & 29 & 85,3 & 34 \\
$2-7$ & 59 & 89,4 & 66 \\
$8-15$ & 62 & 92,5 & 67 \\
$16-20$ & 27 & 90,0 & 30 \\
$21-30$ & 27 & 87,1 & 31 \\
$31-40$ & 21 & 84,0 & 25 \\
$41-50$ & 25 & 89,3 & 28 \\
$51-60$ & 11 & 84,6 & 13 \\
$>60$ & 16 & 72,7 & 22 \\
Total & 277 & 87,6 & 316 \\
\hline
\end{tabular}

Tabela 2

Distribuição da prevalência por parasito em 316 amostras de fezes.

Novo Airão, Amazonas.

\begin{tabular}{lrr}
\hline \multirow{2}{*}{ Parasito } & \multicolumn{2}{c}{ Prevalência } \\
& $\mathrm{n}$ & $\%$ \\
\hline Ascaris lumbricoides & 111 & 35,1 \\
Entamoeba histolytica & 92 & 29,1 \\
Giardia lamblia & 55 & 17,4 \\
Trichuris trichiura & 15 & 4,7 \\
Ancilostomídeos & 13 & 4,7 \\
Strongyloides stercoralis & 8 & 2,5 \\
Enterobius vermicularis & 3 & 0,1 \\
\hline
\end{tabular}

três parasitos e apenas três pacientes apresentavam quatro parasitos.

As pessoas usuárias de água da COSAMA estavam mais infectadas por protozoários (62,2\%), $\mathrm{p} \varangle 0,01$, do que aqueles que utilizavam água de poço coletivo $(47,1 \%)$ ou de poço individual (50\%). Esta maior freqüência deveu-se à Entamoeba histolytica $(36,5 \%)$ e à Giardia lamblia $(20,8 \%)$. Não houve diferença em relação à infecção pelos helmintos (Tabela 3).

\section{Infecção chagásica}

De 346 pacientes cujo soro foi examinado pelas técnicas de imunofluorescência indireta e pelo Elisa, 16 (4,6\%) foram positivos por ambas as técnicas, dez dos quais "reconheceram" o triatomíneo em uma amostra de Rhodnius, Panstrongylus e Triatoma que Ihes foi mostrada. Entretanto, não souberam precisar os locais onde os encontraram; apenas três indivíduos $(0,7 \%)$ referiram já terem sido picados pelo barbeiro em piaçabais onde trabalharam.

\section{Discussão}

O sistema de abastecimento de água em Novo Airão é muito precário. Apenas $25,8 \%$ das casas têm água encanada, de má qualidade e sem nenhum tratamento, refletindo o alto índice de parasitos de veiculação hídrica, particularmente para as pessoas que utilizam "poços artesianos" ou água distribuída pela COSAMA. Por outro lado, $14,6 \%$ das famílias lançam as fezes a céu aberto e $51 \%$ têm apenas uma fossa rudimentar, contribuindo para a contaminação do solo e da água.

Com relação às parasitoses intestinais verifica-se um alto índice daquelas transmitidas através da água e alimentos como o A. lumbricoides $(35,1 \%)$, E. histolytica $(29,1 \%)$ e Giardia Iamblia $(17,4 \%)$ e menor índices por penetração de larvas, como ancilostomídeos $(4,7 \%)$ e S. stercoralis $(2,5 \%)$, possivel mente devido à inadequação do solo para a sua proliferação. A prevalência global das parasitoses intestinais encontradas em Novo Airão $(87,6 \%)$ foi bem mais elevada do que a observada em trabal hos anteriores, tanto em Coari $(68,9 \%)$, no Rio Solimões, como em Barcelos (69,4\%), no Rio Negro, correndo essa diferença em grande parte pela alta prevalência de E. histolytica e G. Iamblia, que foi respectivamente de $29,1 \%$ e $17,4 \%$ em Novo Airão, de $19,7 \%$ e 5,7\% em Barcelos, e de apenas 6,2\% e 3,4\% em Coari (Coura et al., 1993b, 1994c).

A maior prevalência de protozoonoses intestinais no grupo de pessoas cujo o abasteci- 
mento de água era feito pela COSAMA nos faz supor que esta rede de água não tratada possa estar servindo como local de contaminação. Contudo, tal comprovação necessita de investigação específica.

A prevalência sorológica de anticorpos anti-T. cruzi de 4,6\% observada na amostra da população estudada em Novo Airão, não relacionada claramente ao reconhecimento do triatomíneo e do seu local de encontro, deve-se provavelmente, em grande parte, a reações cruzadas com outras infecções, entre as quais com a leishmaniose tegumentar americana. É possível que nos três casos que reconheceram o triatomíneo e disseram ter sido picado pelo inseto haja uma relação direta entre a presença de anticorpos e a infecção pelo T. cruzi. Em Barcelos, no Médio Rio Negro, encontramos uma elevada prevalência sorológica de anticorpos anti-T. cruzi (Coura et al., 1995a, 1995b). Uma grande parte desses anticorpos era heteróloga, entre os quais a laminina induzida por outras infecções, particularmente pela leishmaniose tegumentar americana e, talvez, pela própria malária.

Em Barcelos, entretanto, grande parte das infecções eram causadas pelo próprio T. cruzi e pelo Trypanosoma rangeli, transmitido pelo Rhodnius brethesi aos colhedores de piaçava e suas famílias nos piaçabais, onde residem durante a colheita, e mesmo durante o transporte, trazidos nos rolos da fibra.

Outras doenças foram também mencionadas na história patológica pregressa durante a

\section{Agradecimentos}

Os autores agradecem ao Instituto de Medicina Tropical e à Universidade do Amazonas pelo apoio logístico no trabalho de campo e aos técnicos Nelson Fé e Raimundo Silva de Lima, respectivamente pelos estudos entomológicos e coprológicos. Os autores também agradecem o auxílio do Conselho Nacional de Desenvolvimento Científico e Tecnológico (CNPq).
Tabela 3

Distribuição da freqüência de helmintos e protozoários em amostras de fezes de 316 pessoas em relação à fonte de abastecimento de água, Novo Airão, AM, 1995.

\begin{tabular}{|c|c|c|c|c|c|c|}
\hline \multirow{2}{*}{$\begin{array}{l}\text { Abastecimento } \\
\text { de água }\end{array}$} & \multicolumn{2}{|c|}{ Pacientes } & \multicolumn{2}{|c|}{ Helmintos } & \multicolumn{2}{|c|}{ Protozoários } \\
\hline & $\mathrm{n}$ & $\%$ & $\mathrm{n}$ & $\%$ & $n$ & $\%$ \\
\hline COSAMA & 82 & 25,8 & 36 & $44,0 *$ & 51 & $62,2^{*}$ \\
\hline Poço coletivo & 170 & 53,9 & 77 & 45,3 & 80 & 47,1 \\
\hline Poço individual & 60 & 19,1 & 27 & 45,0 & 30 & 50,0 \\
\hline Outros & 04 & 1,2 & 06 & $-* *$ & 03 & 75,0 \\
\hline Total & 316 & 100 & 146 & 46,2 & 164 & 51,9 \\
\hline
\end{tabular}

$* \mathrm{p}<0,01$

** N as infecções pelos helmintos e protozoários foi considerado cada espécie isoladamente.

investigação em Novo Airão, destacando-se entre elas a malária, a leishmaniose tegumentar americana (LTA), a tuberculose, a hanseníase e a hepatite por vírus, identificando-se apenas um caso de LTA, um de tuberculose, e outro de hanseníase em tratamento durante esta investigação.

Este trabalho faz parte de uma linha de pesquisa sobre parasitoses intestinais e suas relações com o saneamento ambiental, de um lado, e, de outro, sobre a emergência da infecção chagásica em áreas do Rio Negro, no Estado do Amazonas, riscos potenciais de sua urbanização por adaptação de triatomínios silvestres ao domicílio humano, fato que está sendo investigado no momento.

\section{Referências}

ALMEIDA, F. D., 1971. Triatomíneos da Amazônia. Encontro de três espécies naturalmente infectadas por Trypanosoma semel hante ao cruzi, no Estado do Amazonas (Hemiptera, Reduviidae). Acta Amazonica, 1:89-93.

BARRETT, T. V. \& GUERREIRO, J. C. H., 1991. Os triatomíneos (Hemiptera, Reduviidae) em relação à doença de Chagas na Amazônia. In: Bases Científicas para Estratégia de Prevenção e Desenvolvimento da Amazônia; Fatos e Perspectivas (A. L. Val, R. Figlioulo \& R. Feldberg, ed.), pp. 119-130, Manaus: Instituto Nacional de Pesquisas da Amazônia.

BRAZIL, R. P.; SILVA, A. F.; ALBARELLI, A. \&VALLE, J. F., 1985. Distribuição e infecção de triatomíneos por Trypanosoma cruzi na llha de São Luís, Maranhão. Revista da SociedadeBrasileira de Medicina Tropical, 18:257-260.

CHAGAS, C., 1924. Infection naturelle des singes du Pará (Crysotrix sciureus) par Trypanosoma cruzi. Sciencia Médica, 2:75-76. 
COSTA, O. R., 1947. Incidência de parasitos intestinais em quatro cidades da Amazônia. Revista do Serviço Especial de Saúde Pública, 1:203-219.

COURA, J. R., 1990. The risk of endemic Chagas'disease in the Brazilian Amazon: Risk or hypothesis? Revista da Sociedade Brasileira de Medicina Tropical, 23:67-70.

COURA, J. R.; WILLCOX, H. P. F.; ALBUQUERQUE, B. C.; LORENZI, A. G.; BARROSO, D. E.; LALAMA, E. M. E.; GONÇALVES, E. G. R.; GUERRA, J. A. O.; VACA-M ARIN, M. A. \& SÁ-NETO, R. P., 1993a. Aspectos epidemiológicos, sociais e sanitários em áreas do Médio Solimões. I. Estudo nas localidades de São Francisco do Laranjal, Aranaí e São Lázaro do Surubim, Município de Coari, Amazonas. Anais da Academia Nacional de Medicina, 153:122-126.

COURA, J. R.; WILLCOX, H. P. F.; TAVARES, A. M.; CASTRO, J. A. F.; FREITAS, A. D. A.; PLASENCIA, E. P. \& LOAIZA, L. B., 1993b. Aspectos epidemiológicos, sociais e sanitários em áreas do Médio Solimões. II. Estudo de dois bairros periféricos da cidade de Coari e quatro localidades do lago do Mamiá, Estado do Amazonas. Anais da Academia Nacional de Medicina, 153:183-186.

COURA, J. R.; BARRETT, T. V. \& ARBOLEDA, M. N., 1994a. Ataque de populações humanas por triatomíneos silvestres no Amazonas: Uma nova forma de transmissão da infecção chagásica? Revista da Sociedade Brasileira de Medicina Tropical, 27:251-253.

COURA, J. R.; JUNQUEIRA, A. C. V.; GIORDANO, C. M. \& FUNATSU, I. R. K., 1994b. Chagas' disease in the Brazilian Amazon. I. A short review. Revista do Instituto de Medicina Tropical de São Paulo, 36: 63-368.

COURA, J. R.; WILLCOX, H. P. F.; TAVARES, A. M.; PAIVA, D. D.; FERNANDES, O.; RADA, E. L. J. C.; PEREZ, E. P.; BORGES, L. C. L.; HIDALGO, M. E. C. \& NOGUEIRA, M. L. C., 1994c. Aspectos epidemiológicos, sociais e sanitários de uma área no Rio Negro, Estado do Amazonas, com especial referência às parasitoses intestinais e à infecção chagásica. Cadernos de Saúde Pública, 10:327-336.

COURA, J. R.; ARBOLEDA, M. N. \& WILLCOX, H. P. F., 1995a. Chagas'disease in the Brazilian Amazon. II. A serological survey. Revista do Instituto de Medicina Tropical de São Paulo, 37:103-107.

COURA, J. R.; WILLCOX, H. P. F.; ARBOLEDA, M. N.; FERNANDES, O. \& PAIVA, D. D., 1995b. Chagas' disease in the Brazilian Amazon. III. A cross-sectional study. Revista do Instituto de Medicina Tropical deSão Paulo, 37:415-420.

DEANE, L. M., 1961. Tripanosoma de mamíferos da região amazônica. I. Alguns flagelados encontrados no sangue de mamíferos silvestres do Estado do Pará. Revista do Instituto de Medicina Tropical deSão Paulo, 3:15-28.

DEANE, L. M., 1964. Tripanosomídeos de mamíferos da região amazônica. III. Hemoscopia e xenodiagnóstico de animais silvestres nos arredores de Belém, Pará. Revista do Instituto de Medicina Tropical deSão Paulo, 6:225-232.
DEANE, L. M., 1967. Tripanosomídeos de mamíferos da região amazônica. IV. Hemoscopia e xenodiagnóstico de animais silvestres da estrada BelémBrasília. Revista do Instituto de Medicina Tropical deSão Paulo, 9:143-148.

DEANE, L. M. \& DAM ASCENO, R., 1961. Tripanosomídeos de mamífero da região amazônica. II. Tripanosomas de macacos da zona de Salgado, Estado do Pará. Revista do Instituto de Medicina Tropical deSão Paulo, 3:61-70.

DIAS, L. C. S.; DELHOME-FILHO, J.; PAES, M. G.; FANAS, A. N. \& AGUIAR, J. C. S., 1991. Prevalência de parasitos intestinais em habitantes do Rio Negro, Estado do Amazonas, Brasil. Acta Amazonica, 12:65-70.

IBGE (Fundação Instituto Brasileiro de Geografia e Estatística), 1991. Recenseamento Geral do Brasil. Censo Demográfico do Amazonas. Brasília: IBGE.

LUTZ, A., 1919. O Schistosoma e a schistosomose segundo observações feitas no Brasil. Memórias do Instituto Oswaldo Cruz, 11:121-150.

MILES, M. A.; SOUZA, A. A. \& PÓVOA, M., 1981. Chagas' disease in the Amazon Basin: III. Ecotopes of ten triatomine bug species (Hemiptera, Reduviidae) from the vicinity of Belém, Pará State, Brazil. Journal of Medical Entomology, 18:266-278.

MILES, M. A.; ARIAS, J. R. \& SOUZA, A. A., 1983. Chagas' disease in the Amazon Basin. V. Periurban palms as habitats of Rhodnius robustus and Rhodnius pictipes, triatominae vectors of Chagas' disease. Memórias do Instituto Oswaldo Cruz, 78:391-398.

MORAES, M. A. P., 1959. Inquérito sobre parasitos intestinais na cidade de Codajás, Estado do Amazonas. Revista Brasileira de Medicina, 16:488-491.

MONTENEGRO, L., 1947. Incidência de protozoários e helmintos em Manaus. Revista Brasileira de Medicina, 4:266-268.

MONTORIL-FILHO, M.; FERRARONI, J. J. \& MONTORIL, D. A. A., 1978. Diagnóstico sócio-parasitosanitário na cidade de Nova Olinda do Norte, Amazonas. Acta Amazonica, 8:91-98.

OLIVEIRA, W. R., 1959. Contribuição ao estudo coprológico na cidade de Manaus. Brasil Médico, 73: 123-125.

PINHEIRO, M. F. S.; VASCONCELOS, J. C. \& WANDEL, D. E., 1976. Contribuição ao estudo de parasitos intestinais em dois bairros de Manaus, Amazonas. Acta Amazonica, 6:67-73.

SHAW, J.; LAINSON, R. \& FRAHIA, H., 1969. Considerações sobre a epidemiologia dos primeiros casos autóctones de doença de Chagas registados em Belém, Pará, Brasil. Revista de Saúde Pública, 3: 153-157.

VALENTE, S. A. S. \&VALENTE, V., 1993. Situação atual da doença de Chagas na Amazônia. Revista da Sociedade Brasileira de Medicina Tropical, 26:68-70.

VALENTE, S. A. S.; VALENTE, V. C.; PINTO, A. Y. N. \& CRESCENTE, J. A. B., 1997. Doença de Chagas. In: Tratado de Infectologia (R. Veronesi \& R. Focaccia, ed.), pp. 1501-1503, São Paulo: Editora Atheneu. 